\title{
Assessment of contamination using an ATP bioluminescence assay on doorknobs in a university-affiliated hospital in Japan
}

\author{
Naoko Kajigaya ${ }^{1 \dagger}$, Yoneji Hirose ${ }^{1,2 \dagger}$, Shinta Koike 2 , Tomohiro Fujita ${ }^{1,2}$, Norio Yokota', Satsuki Hata', \\ Makoto Ikenaga ${ }^{1}$, Noritada Kobayashi ${ }^{1}$ and Takashi Takahashi, ${ }^{1,3}$
}

\begin{abstract}
Background: Doorknobs are inevitable points of hand contact. We monitored doorknob contamination in a university hospital using an ATP bioluminescence assay and stamp agar method. We selected grip-, lever-, push-, insert-, and two-pull-type doorknobs in staff lavatories and break rooms, a linen closet, dirty utility rooms, a newborn care unit, clinical lavatories and examination rooms, dressing rooms for radiological tests, and lavatories for health examination, as monitoring points in wards and clinics. Sequential monitoring with an ATP assay (six times) and culture (once) were performed at the same time of day in autumn, winter, and summer. We provided contamination data to appropriate healthcare providers and housekeepers, and queried the staff regarding decontamination of doorknobs.

Results: When comparing ATP values on the same type of doorknobs, significant differences in contamination were demonstrated among several clinical rooms and several rooms in wards during all three seasons. No correlation was observed between ATP values on clinical-examination-room doorknobs and outpatient numbers, or between ATP values at any monitoring point and microbial colony-forming units. ATP values on clinical-examination-room doorknobs were reduced after cleaning according to instructions.
\end{abstract}

Conclusions: ATP assay is useful for measuring baseline doorknob contamination in clinical rooms. Our findings confirm the need to improve routine decontamination in clinical departments. We need to analyze further the relationship between hospital-acquired infections and doorknob contamination, as assessed by ATP assay in clinics.

Keywords: Doorknob, Contamination, ATP bioluminescence assay, Stamp culture, University hospital

\section{Background}

The spread of healthcare-associated pathogens, such as methicillin-resistant Staphylococcus aureus and vancomycin-resistant Enterococcus, most frequently occurs through the transiently contaminated hands of healthcare providers [1]. Additionally, environmental contamination in clinics contributes to the transmission of healthcareassociated pathogens [2-4]. Hospital-acquired infections (HAIs) can develop via microbe-contaminated

\footnotetext{
*Correspondence: taka2si@lisci.kitasato-u.ac.jp

${ }^{\dagger}$ Naoko Kajigaya and Yoneji Hirose contributed equally to this work

${ }^{3}$ Laboratory of Infectious Diseases, Graduate School of Infection Control Sciences, Kitasato University, 5-9-1 Shirokane, Minato-ku, Tokyo 108-8641, Japan

Full list of author information is available at the end of the article
}

environmental surfaces that are frequently touched by hands, such as doorknobs, guardrails in corridors, and over-bed tables [5]. Thus, efforts to improve hand hygiene and isolation practices have routinely been implemented to prevent and control HAIs [5]. Healthcare providers also need to pay close attention to ensure adequate cleaning and disinfection of the hospital environment because these are significant parts of infection control programs [6].

Based on the concept of environmental cleaning and disinfection, recommendations and standards to improve hospital cleanliness have been published [7-9]. These guidelines recommend cleaning and disinfection of environmental surfaces in the proximity of patients, as well as surfaces that are likely to be touched by the patients, 
healthcare providers, or housekeepers. However, routine housekeeping practices are often suboptimal [10]. Therefore, increased attention should be paid to the effectiveness of cleaning protocols.

Approaches to monitoring the effectiveness of cleaning procedures include: (1) visual assessment of surfaces; (2) application of fluorescent dye to surfaces with subsequent assessment of residual dye after cleaning; (3) determination of aerobic colony-forming units (CFUs); and (4) detection of ATP on surfaces [11]. Detection of ATP, which is present in all types of organic material, including bacteria, food, and human secretions and excretions, on environmental surfaces, is used in the food and beverage industries to evaluate the adequacy of cleaning protocols [12]. The ATP bioluminescence assay as an indicator of general organic contamination $[11,13,14]$ and the standard stamp agar method for monitoring microbiological contamination $[14,15]$ are both available to monitor hospital contamination. However, few investigators have used these methods to monitor doorknob contamination in medical settings, especially clinical departments.

Doorknobs are inevitable points of hand contact in domestic environments. In medical settings, there is a variety of doorknobs, including grip-, lever-, pull-, push-, and insert-types. Few studies have compared ATP levels on doorknobs surfaces during different monitoring periods. In general, well-cleaned surfaces with little organic material have an ATP yield $<250-300$ relative light units (RLUs), while poorly cleaned surfaces with a large amount of organic material can have $>1,000$ RLUs [11]. In the present study, we determined seasonal variations in contamination of various types of doorknobs in a university-affiliated hospital, using the ATP bioluminescence assay.

\section{Methods}

Determination of doorknob types and monitoring points Before starting the monitoring of doorknob contamination, we determined the types of doorknobs to be assessed (i.e., grip-, lever-, pull-, push-, and insert-types) and the monitoring points to be evaluated (e.g., inpatient wards and outpatient clinics) in our 372-bed tertiary-care hospital. We prepared a list of all the doorknob types in the hospital: grip-type (a), lever-type (b), two pull-types (c1, c2), push-type (d), and insert-type (e) (Fig. 1), and then each member of the infection control team (ICT) chose a single type of doorknob. We selected the monitoring points to compare the level of contamination on different doorknob types in two different healthcare settings, inpatient wards and outpatient clinics. We chose 16 monitoring points in each of the wards and clinics (Table 1). There were no inaccessible locations because the sampling spots were limited and did not include clean rooms or patient treatment rooms. We did not explain the determination of monitoring points to the corresponding healthcare providers and housekeepers before starting this investigation, to avoid a monitoring effect on cleaning and to comprehend baseline data.

\section{Frequency and season of monitoring of doorknob contamination}

We performed the monitoring between 17:00 and 18:00 $\mathrm{h}$ on every Tuesday for 7 weeks in three different seasons. The ATP bioluminescence assay and standard stamp agar method were carried out six times and once out of seven times during the same monitoring period, respectively. Our main assessment was of contamination with organic material (bacteria, food, and human secretions and excretions) using the ATP assay, and the stamp agar method was used in a confirmatory manner for bacterial isolation. The monitoring seasons were: October to November (autumn) 2013, January to March (winter) 2014, and June to July (summer) 2014 because incidences of bacterial gastroenteritis and food poisoning were presumed to have seasonal variation. The same ICT members performed the sampling and assessment with the ATP assay and stamp agar culture. Outpatients alone touched the doorknobs of the clinical examination rooms, and the number of visiting outpatients was estimated to be equal to the frequency of touch of the doorknobs. We also analyzed the correlation between ATP values on the clinical doorknobs and the number of outpatients.

\section{ATP bioluminescence assay}

This assay was done using a Lumitester PD-20 (Kikkoman Biochemifa, Tokyo, Japan). We selected this device
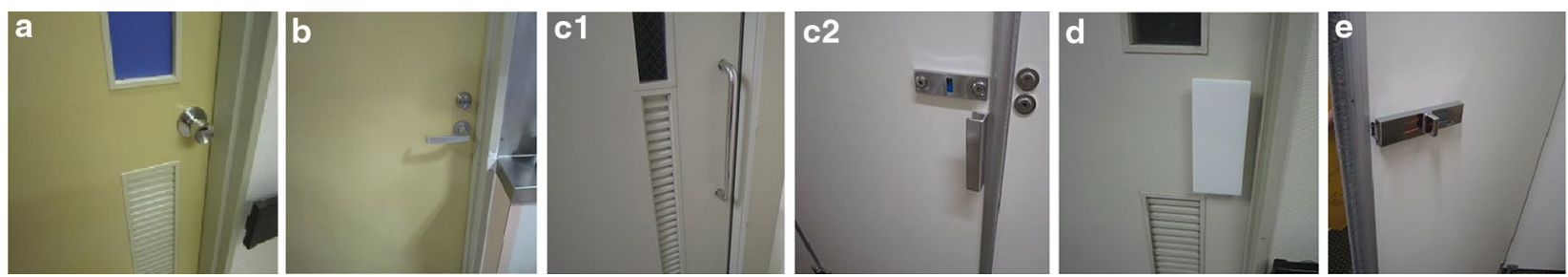

Fig. 1 Grip-type (a), lever-type (b), two pull-types (c1, c2), push-type (d), and insert-type (e) of doorknobs. They were selected by all members of infection control team. 
because it was one of most popular devices in Japan. The samples were collected by wiping a $3.5 \times 3.5 \mathrm{~cm}$ area (roughly equivalent to the area of a stamp agar plate) of each doorknob with a specialized swab provided by the assay (LuciPac Pen), and the ATP values of the swabs were measured immediately. The same ICT member collected the samples from each area throughout this study, to avoid wiping bias. We also measured the ATP values on an uncontaminated grip-type doorknob (six times). This type was chosen because the grip-type was only available as an experimental model.

\section{Standard stamp agar method}

A commercially available stamp agar plate (DD Checker Soybean Casein Digest Agar Plate; Kyokuto Pharmaceutical Industrial Co., Ltd., Tokyo, Japan) was used to monitor microbial contamination on each doorknob $\left(10-\mathrm{cm}^{2}\right.$ area roughly equivalent to the ATP wiping area). The stamp agar method was also performed by the same ICT member who did the wiping throughout the study, to avoid bias in wiping and stamping. The stamped agar plates were immediately cultured for 24-72 h under aerobic conditions with moisture at $35^{\circ} \mathrm{C}$, and colonies were counted. The data were estimated as CFU per $10 \mathrm{~cm}^{2}$. We also identified microorganisms to the genus or species level. Correlations between ATP values and microbial counts on the doorknobs were analyzed.

\section{Feedback of contamination data to healthcare providers and housekeepers}

After completing the monitoring, we provided the contamination data to the appropriate healthcare providers and housekeepers. The time of cleaning, disinfectants used, and how to clean the environment were investigated in detail through the interview with the staff and inspection of the environment when cleaning. If high ATP values were found, we instructed the relevant individuals on optimal cleaning methods using the established manual. In such cases, we assessed whether the ATP values were reduced, using measurement by the same ICT member using the same sampling method at 17:00-18:00 h 1 week after instruction.

\section{Ethical considerations}

The study protocol was approved by the ethical committee of Kitasato Medical Center before starting the investigation. During the sample and data collection, we protected the privacy and confidentiality of the personal information, under supervision of the hospital manager.

\section{Statistical analysis}

Data collected from all of the samples were transferred to the program Excel Add-in for statistical analysis. The data concerning RLU were expressed as the mean \pm standard deviation and range (minimum to maximum). When comparing the ATP values on the same type of doorknob at different monitoring points during the same study period, the data were analyzed using the Mann-Whitney $U$ test, as previously described [11]. Spearman's correlation index $\gamma$ was calculated using statistical analysis software. A $p$ value of $<0.05$ was considered to be statistically significant.

\section{Results}

ATP values and microbial CFU on several doorknob types in wards and clinics in different seasons

ATP values on uncontaminated grip-type doorknobs using the simulation were $24 \pm 11$ (12-41) RLU, which were the negative control levels. The relationship between ATP values and microbial CFU per $10 \mathrm{~cm}^{2}$ of several doorknob types is shown for the three different seasons (Table 1).

When comparing ATP values on lever-type (b) doorknobs, there was a significant difference in contamination between the clinical examination rooms and staff break rooms in the wards during each season (average RLU; 4,733 vs. 426 in autumn, 2,371 vs. 413 in winter, and 2,270 vs. 666 in summer). In addition, there was a significant difference in ATP values on grip-type (a) doorknobs of dressing rooms for radiological tests, as compared with the same type of doorknobs of staff lavatories in the wards during each of the three seasons. In contrast, there was no significant difference in ATP values on pull-type (c1) doorknobs of dirty utility rooms in the wards and the same type of doorknobs of staff break rooms during each of the three seasons.

\section{Identification of microbes in wards and clinics by type of doorknobs}

The types and numbers of microorganisms in wards and clinics according to type of doorknob are shown in Table 2. When it was impossible to identify the microbial genus or species, we described them as non-fermentative rods, Gram-positive rods, Gram-positive cocci, and fungi. The main types of microbes attached to the various doorknobs were coagulase-negative Staphylococcus, Bacillus, Corynebacterium, and Micrococcus in both wards and clinics.

\section{Correlation between ATP values on clinical booth doorknobs and outpatient numbers}

We determined the correlation between ATP values on clinical booth doorknobs and outpatient numbers in the three seasons (Fig. 2). We found no strong correlation (correlation index $\gamma=0.066$ ). 
Table 1 ATP values and microbial colony-forming unit on several doorknob types in wards and clinics in different seasons

\begin{tabular}{|c|c|c|c|c|c|}
\hline Position in hospital & $\begin{array}{l}\text { Monitoring point } \\
\text { of doorknob }\end{array}$ & $\begin{array}{l}\text { Type of } \\
\text { doorknobs }\end{array}$ & $\begin{array}{l}\text { Mean } \pm \text { SD } \\
\text { of ATP values } \\
(R L U)\end{array}$ & $\begin{array}{l}\text { Range of } \\
\text { ATP values } \\
\text { (RLU) }\end{array}$ & $\begin{array}{l}\text { Microbial } \\
\text { CFU per } \\
10 \mathrm{~cm}^{2}\end{array}$ \\
\hline \multicolumn{6}{|l|}{$<$ October to November, 2013> } \\
\hline \multirow[t]{2}{*}{ 3rd floor in southern building } & Staff lavatory & $A^{* *}$ & $404 \pm 125$ & $230-618$ & 0 \\
\hline & Staff break room & $B^{*}$ & $551 \pm 251$ & $250-860$ & 1 \\
\hline \multirow[t]{3}{*}{ 4th floor in southern building } & Staff lavatory & $A^{* *}$ & $334 \pm 207$ & $157-756$ & 1 \\
\hline & Staff break room & $B^{*}$ & $310 \pm 204$ & $107-740$ & 8 \\
\hline & Linen closet & A & $794 \pm 308$ & $421-1342$ & 2 \\
\hline \multirow[t]{2}{*}{ 4th floor in southern building } & Staff lavatory & $A^{* *}$ & $249 \pm 161$ & $101-544$ & 1 \\
\hline & Staff break room & $B^{*}$ & $417 \pm 112$ & $217-567$ & 0 \\
\hline 5th floor in southern building & Staff lavatory & $A^{* *}$ & $365 \pm 147$ & $171-642$ & 3 \\
\hline \multirow[t]{2}{*}{ 2nd floor in northern building } & Dirty utility room & $\mathrm{C} 1$ & $512 \pm 232$ & $212-821$ & 3 \\
\hline & Staff break room & $\mathrm{C} 1$ & $429 \pm 194$ & $144-788$ & 2 \\
\hline \multirow[t]{2}{*}{ 3rd floor in northern building } & Dirty utility room & $\mathrm{C} 1$ & $327 \pm 193$ & $129-614$ & 4 \\
\hline & Staff break room & $\mathrm{C} 1$ & $451 \pm 172$ & $221-734$ & 3 \\
\hline \multirow[t]{2}{*}{ 4th floor in northern building } & Dirty utility room & $\mathrm{C} 1$ & $351 \pm 108$ & $156-463$ & 4 \\
\hline & Staff break room & C1 & $290 \pm 80$ & $203-436$ & 0 \\
\hline \multirow[t]{2}{*}{ 5th floor in northern building } & Dirty utility room & C1 & $271 \pm 159$ & $127-534$ & 3 \\
\hline & Newborn care unit & $\mathrm{C} 1$ & $216 \pm 62$ & $147-296$ & 4 \\
\hline \multirow[t]{11}{*}{ Clinic of internal medicine } & Western-style lavatory for men & C2 & $2536 \pm 744$ & 1369-3490 & 7 \\
\hline & Western-style lavatory for men & E & $927 \pm 295$ & $433-1443$ & 22 \\
\hline & Japanese-style lavatory for men & C2 & $1176 \pm 698$ & $314-2511$ & 11 \\
\hline & Japanese-style lavatory for men & $\mathrm{E}$ & $923 \pm 351$ & $570-1515$ & 25 \\
\hline & Western-style lavatory for women & $\mathrm{C} 2$ & $1323 \pm 615$ & $543-2291$ & 12 \\
\hline & Western-style lavatory for women & $\mathrm{E}$ & $364 \pm 227$ & $187-857$ & 6 \\
\hline & Japanese-style lavatory for women & $\mathrm{C} 2$ & $2278 \pm 2981$ & $363-8886$ & 3 \\
\hline & Japanese-style lavatory for women & $E$ & $607 \pm 629$ & $243-2004$ & 7 \\
\hline & $\begin{array}{l}\text { Examination room for general internal } \\
\text { medicine }\end{array}$ & $B^{*}$ & $1702 \pm 455$ & $1109-2355$ & 4 \\
\hline & Examination room for nephrology & $B^{*}$ & $2109 \pm 1560$ & $745-5434$ & 30 \\
\hline & Examination room for gastroenterology & $B^{*}$ & $10387 \pm 8096$ & $2745-26425$ & 14 \\
\hline \multirow[t]{3}{*}{ Department of radiology } & Dressing room 1 for radiological tests & $A^{* *}$ & $668 \pm 299$ & $331-1244$ & 1 \\
\hline & Dressing room 2 for radiological tests & $A^{* *}$ & $356 \pm 92$ & $214-529$ & 0 \\
\hline & Dressing room 3 for radiological tests & $A^{* *}$ & $679 \pm 146$ & $513-953$ & 0 \\
\hline \multirow{2}{*}{$\begin{array}{l}\text { Department for health } \\
\text { examination }\end{array}$} & Lavatory for men & $\mathrm{D}$ & $488 \pm 157$ & 218-705 & 4 \\
\hline & Lavatory for women & $\mathrm{D}$ & $216 \pm 59$ & $119-284$ & 2 \\
\hline \multicolumn{6}{|l|}{$<$ January to March, 2014> } \\
\hline \multirow[t]{2}{*}{ 3rd floor in southern building } & Staff lavatory & $A^{* *}$ & $360 \pm 246$ & $173-843$ & 10 \\
\hline & Staff break room & $B^{*}$ & $668 \pm 321$ & $314-1099$ & 2 \\
\hline \multirow[t]{3}{*}{ 4th floor in southern building } & Staff lavatory & $A^{* *}$ & $4393 \pm 6443$ & $166-14174$ & 8 \\
\hline & Staff break room & $B^{*}$ & $719 \pm 793$ & $144-2125$ & 5 \\
\hline & Linen closet & A & $598 \pm 171$ & $327-829$ & 0 \\
\hline \multirow[t]{2}{*}{ 4th floor in southern building } & Staff lavatory & $A^{* *}$ & $203 \pm 87$ & $104-345$ & 3 \\
\hline & Staff break room & $B^{*}$ & $229 \pm 49$ & $200-327$ & 10 \\
\hline 5th floor in southern building & Staff lavatory & $A^{* *}$ & $444 \pm 290$ & $278-1025$ & 2 \\
\hline \multirow[t]{2}{*}{ 2nd floor in northern building } & Dirty utility room & $\mathrm{C} 1$ & $1495 \pm 2588$ & 194-6759 & 0 \\
\hline & Staff break room & $\mathrm{C} 1$ & $455 \pm 436$ & $125-1284$ & 1 \\
\hline \multirow[t]{2}{*}{ 3rd floor in northern building } & Dirty utility room & $\mathrm{C} 1$ & $551 \pm 295$ & $271-1069$ & 17 \\
\hline & Staff break room & $\mathrm{C} 1$ & $484 \pm 212$ & $238-721$ & 0 \\
\hline
\end{tabular}


Table 1 continued

\begin{tabular}{|c|c|c|c|c|c|}
\hline Position in hospital & $\begin{array}{l}\text { Monitoring point } \\
\text { of doorknob }\end{array}$ & $\begin{array}{l}\text { Type of } \\
\text { doorknobs }\end{array}$ & $\begin{array}{l}\text { Mean } \pm \text { SD } \\
\text { of ATP values } \\
(R L U)\end{array}$ & $\begin{array}{l}\text { Range of } \\
\text { ATP values } \\
\text { (RLU) }\end{array}$ & $\begin{array}{l}\text { Microbial } \\
\text { CFU per } \\
10 \mathrm{~cm}^{2}\end{array}$ \\
\hline \multirow[t]{2}{*}{ 4th floor in northern building } & Dirty utility room & C1 & $358 \pm 119$ & $147-467$ & 2 \\
\hline & Staff break room & $\mathrm{C} 1$ & $301 \pm 185$ & $153-654$ & 1 \\
\hline \multirow[t]{2}{*}{ 5th floor in northern building } & Dirty utility room & $\mathrm{C} 1$ & $541 \pm 1056$ & $32-2694$ & 0 \\
\hline & Newborn care unit & $\mathrm{C} 1$ & $312 \pm 136$ & $131-492$ & 0 \\
\hline \multirow[t]{11}{*}{ Clinic of internal medicine } & Western-style lavatory for men & $\mathrm{C} 2$ & $2841 \pm 3132$ & $1277-9221$ & 20 \\
\hline & Western-style lavatory for men & E & $1120 \pm 347$ & $804-1725$ & 9 \\
\hline & Japanese-style lavatory for men & $\mathrm{C} 2$ & $1736 \pm 1118$ & $855-3674$ & 63 \\
\hline & Japanese-style lavatory for men & $E$ & $770 \pm 121$ & 604-918 & 6 \\
\hline & Western-style lavatory for women & C2 & $58605 \pm 136900$ & $1466-338031$ & 8 \\
\hline & Western-style lavatory for women & E & $4607 \pm 8044$ & $247-20327$ & 26 \\
\hline & Japanese-style lavatory for women & C2 & $1844 \pm 1786$ & $758-5225$ & 6 \\
\hline & Japanese-style lavatory for women & E & $432 \pm 237$ & 276- 905 & 6 \\
\hline & $\begin{array}{l}\text { Examination room for general internal } \\
\text { medicine }\end{array}$ & $B^{*}$ & $2045 \pm 1228$ & $950-3943$ & 13 \\
\hline & Examination room for nephrology & $B^{*}$ & $2992 \pm 1110$ & $1825-4411$ & 19 \\
\hline & Examination room for gastroenterology & $B^{*}$ & $2076 \pm 731$ & 1499-3494 & 18 \\
\hline \multirow[t]{3}{*}{ Department of radiology } & Dressing room 1 for radiological tests & $A^{* *}$ & $911 \pm 376$ & $511-1412$ & 5 \\
\hline & Dressing room 2 for radiological tests & $A^{* *}$ & $365 \pm 214$ & 205-792 & 6 \\
\hline & Dressing room 3 for radiological tests & $A^{* *}$ & $1959 \pm 1982$ & $497-5883$ & 18 \\
\hline \multirow{2}{*}{$\begin{array}{l}\text { Department for health examina- } \\
\text { tion }\end{array}$} & Lavatory for men & $\mathrm{D}$ & $498 \pm 160$ & $335-803$ & 14 \\
\hline & Lavatory for women & $\mathrm{D}$ & $522 \pm 197$ & $292-853$ & 17 \\
\hline \multicolumn{6}{|l|}{$<$ June to July, 2014> } \\
\hline \multirow[t]{2}{*}{ 3rd floor in southern building } & Staff lavatory & $A^{* *}$ & $492 \pm 171$ & $301-783$ & 5 \\
\hline & Staff break room & $B^{*}$ & $1277 \pm 516$ & $635-2178$ & 2 \\
\hline \multirow[t]{3}{*}{ 4th floor in southern building } & Staff lavatory & $A^{* *}$ & $310 \pm 48$ & $235-372$ & 1 \\
\hline & Staff break room & $B^{*}$ & $526 \pm 428$ & $147-1342$ & 6 \\
\hline & Linen closet & A & $489 \pm 141$ & $327-652$ & 0 \\
\hline \multirow[t]{2}{*}{ 4th floor in southern building } & Staff lavatory & $A^{* *}$ & $272 \pm 117$ & $134-488$ & 1 \\
\hline & Staff break room & $B^{*}$ & $195 \pm 78$ & 70-291 & 9 \\
\hline 5th floor in southern building & Staff lavatory & $A^{* *}$ & $498 \pm 378$ & 108-992 & 0 \\
\hline \multirow[t]{2}{*}{ 2nd floor in northern building } & Dirty utility room & $\mathrm{C} 1$ & $997 \pm 523$ & $415-1615$ & 6 \\
\hline & Staff break room & C1 & $578 \pm 307$ & $79-876$ & 0 \\
\hline \multirow[t]{2}{*}{ 3rd floor in northern building } & Dirty utility room & $\mathrm{C} 1$ & $694 \pm 441$ & $416-1566$ & 8 \\
\hline & Staff break room & C1 & $452 \pm 171$ & $335-795$ & 8 \\
\hline \multirow[t]{2}{*}{ 4th floor in northern building } & Dirty utility room & $\mathrm{C} 1$ & $601 \pm 206$ & $343-892$ & 0 \\
\hline & Staff break room & $\mathrm{C} 1$ & $772 \pm 681$ & $271-2104$ & 3 \\
\hline \multirow[t]{2}{*}{ 5th floor in northern building } & Dirty utility room & $\mathrm{C} 1$ & $233 \pm 108$ & $126-411$ & 0 \\
\hline & Newborn care unit & C1 & $276 \pm 90$ & $137-401$ & 1 \\
\hline \multirow[t]{10}{*}{ Clinic of internal medicine } & Western-style lavatory for men & C2 & $1681 \pm 811$ & $907-3095$ & 3 \\
\hline & Western-style lavatory for men & $\mathrm{E}$ & $1307 \pm 568$ & $809-2388$ & 1 \\
\hline & Japanese-style lavatory for men & C2 & $916 \pm 353$ & $500-1541$ & 31 \\
\hline & Japanese-style lavatory for men & $E$ & $527 \pm 226$ & $84-710$ & 12 \\
\hline & Western-style lavatory for women & C2 & $1454 \pm 1549$ & $531-4583$ & 4 \\
\hline & Western-style lavatory for women & $\mathrm{E}$ & $684 \pm 549$ & $191-1624$ & 39 \\
\hline & Japanese-style lavatory for women & C2 & $989 \pm 283$ & $665-1306$ & 7 \\
\hline & Japanese-style lavatory for women & E & $415 \pm 171$ & $303-759$ & 9 \\
\hline & $\begin{array}{l}\text { Examination room for general internal } \\
\text { medicine }\end{array}$ & $B^{*}$ & $1938 \pm 622$ & $1333-2917$ & 13 \\
\hline & Examination room for nephrology & $B^{*}$ & $2428 \pm 622$ & $1464-3353$ & 81 \\
\hline
\end{tabular}


Table 1 continued

\begin{tabular}{|c|c|c|c|c|c|}
\hline Position in hospital & $\begin{array}{l}\text { Monitoring point } \\
\text { of doorknob }\end{array}$ & $\begin{array}{l}\text { Type of } \\
\text { doorknobs }\end{array}$ & $\begin{array}{l}\text { Mean } \pm \text { SD } \\
\text { of ATP values } \\
\text { (RLU) }\end{array}$ & $\begin{array}{l}\text { Range of } \\
\text { ATP values } \\
\text { (RLU) }\end{array}$ & $\begin{array}{l}\text { Microbial } \\
\text { CFU per } \\
10 \mathrm{~cm}^{2}\end{array}$ \\
\hline \multirow{4}{*}{ Department of radiology } & Examination room for gastroenterology & $\mathrm{B}^{*}$ & $2312 \pm 978$ & $745-3410$ & 116 \\
\hline & Dressing room 1 for radiological tests & $A^{* *}$ & $1165 \pm 594$ & $585-2187$ & 61 \\
\hline & Dressing room 2 for radiological tests & $A^{* *}$ & $572 \pm 262$ & $254-943$ & 5 \\
\hline & Dressing room 3 for radiological tests & $A^{* *}$ & $773 \pm 208$ & $559-1156$ & 3 \\
\hline \multirow{2}{*}{$\begin{array}{l}\text { Department for health examina- } \\
\text { tion }\end{array}$} & Lavatory for men & $\mathrm{D}$ & $999 \pm 635$ & $498-2176$ & 0 \\
\hline & Lavatory for women & D & $1386 \pm 2177$ & $261-5807$ & 2 \\
\hline
\end{tabular}

Type of doorknobs included grip-type (A), lever-type (B), two pull-types (C1 and C2), push-type (D), and insert-type (E).

$S D$ standard deviation, RLU relative light unit, CFU colony-forming unit.

* When comparing ATP values on lever-type doorknobs, there was a significant difference in contamination between the clinical examination rooms and staff break rooms in the wards.

** There was a significant difference in ATP values on grip-type doorknobs of dressing rooms for radiological tests, as compared with the same type of doorknobs of staff lavatories in the wards.

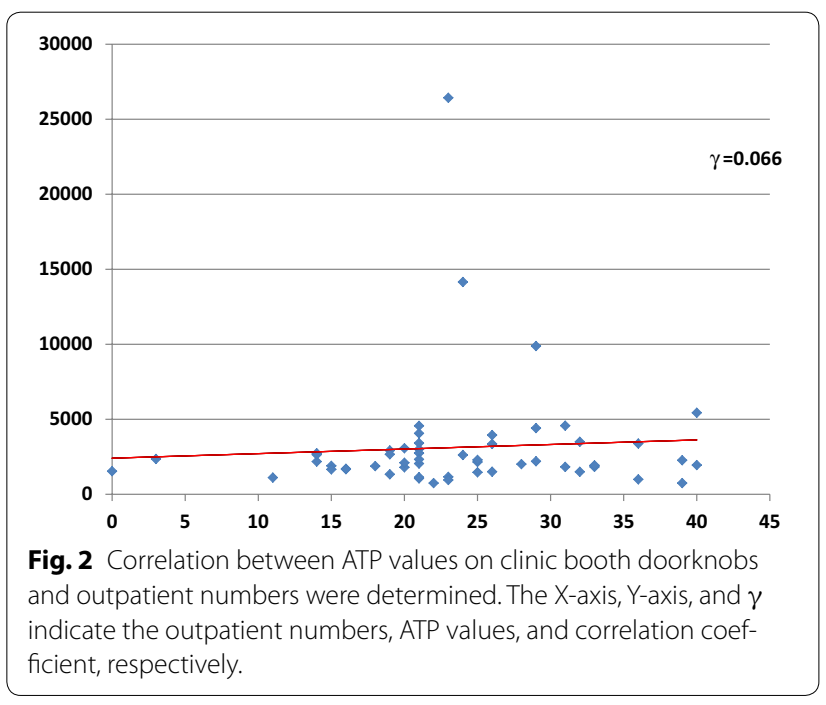

\section{Correlation between ATP values and microbial CFU on doorknobs}

We determined the correlation between mean ATP values of each monitoring point and microbial CFU per $10 \mathrm{~cm}^{2}$ on doorknobs in the three seasonal periods (Fig. 3). We observed no strong correlation (correlation index $\gamma=0.052$ ).

\section{Feedback of contamination data to healthcare providers and housekeepers}

After completion of monitoring, we provided feedback in the form of the collected contamination data to the relevant healthcare providers and housekeepers. The time of cleaning was 07:00-10:00 $\mathrm{h}$ at every point in the wards and clinics, and 19:00-20:00 $\mathrm{h}$ in the clinical examination rooms (general internal medicine, nephrology, and

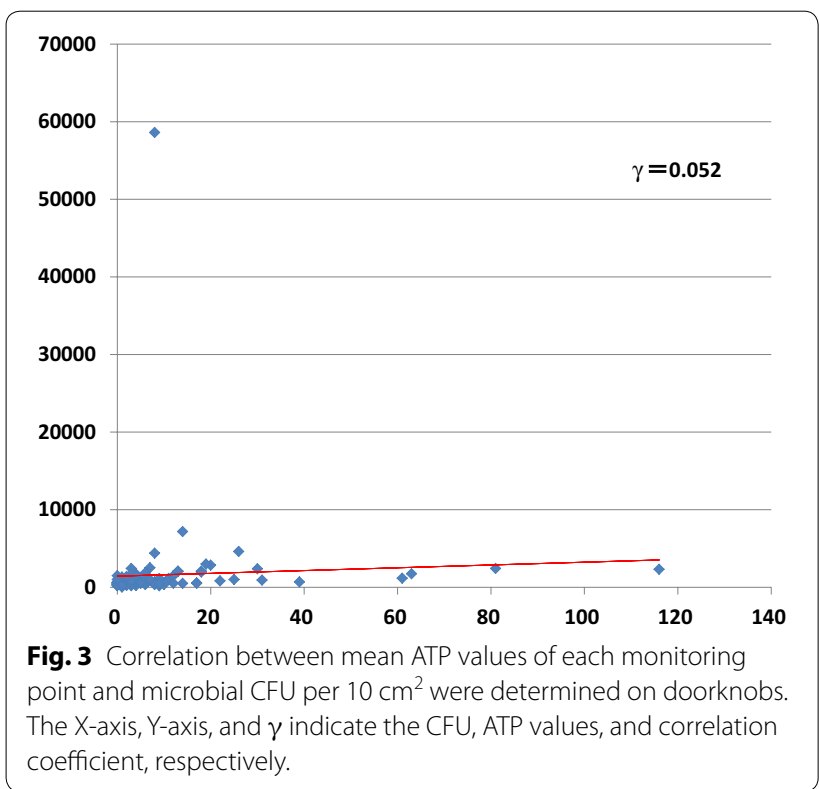

gastroenterology). Quaternary ammonium compounds were used for environmental disinfection. High mean ATP values $>1,000$ RLU were found in the clinical examination rooms and adjacent lavatories with lever-type (b) and pull-type (c2) doorknobs during all study seasons (Table 1). Therefore, we instructed the housekeepers on the recommended cleaning methods. One week after this instruction, the ATP values on doorknobs after cleaning were reduced in the clinical examination rooms $(n=3)$ and adjacent lavatories $(n=4)(693,229,408,731,431$, 274, and 175 RLU, respectively). The second ATP value after instruction was $420 \pm 203$ (175-731) RLU, while the first value before instruction was 5,024 $\pm 30,044$ (314-338,031) RLU (Table 1). 
Table 2 Cumulative data of microbes in wards and clinics by type of doorknobs

\begin{tabular}{|c|c|c|}
\hline Type of doorknobs & $\begin{array}{l}\text { Genus- or species-level identification of organisms } \\
\text { in wards (CFU/10 cm } 2 \text { for each) }\end{array}$ & $\begin{array}{l}\text { Genus- or species-level identification of organisms in clinics } \\
\text { (CFU/10 cm } \mathrm{cm}^{2} \text { for each) }\end{array}$ \\
\hline$A$ & $\begin{array}{l}\text { CNS (10), Corynebacterium (10), Bacillus (6), Micrococcus (6), } \\
\text { NFR (3), Aspergillus sp (1), GPR (1) }\end{array}$ & CNS (80), Micrococcus (16), Corynebacterium (1), NFR (1), GPR (1) \\
\hline $\mathrm{B}$ & CNS (27), Bacillus (9), Micrococcus (6), NFR (1) & $\begin{array}{l}\text { CNS (227), Bacillus (73), GPR (5), Micrococcus (1), B. cereus (1), } \\
\text { Corynebacterium (1) }\end{array}$ \\
\hline C1 & $\begin{array}{l}\text { CNS (33), Micrococcus (15), Bacillus (13), Corynebacterium (3), } \\
\text { GPR (3), NFR (2), Fungi (1) }\end{array}$ & NT \\
\hline $\mathrm{C} 2$ & NT & CNS (130), Bacillus (34), Micrococcus (8), Corynebacterium (3) \\
\hline D & NT & $\begin{array}{l}\text { Bacillus (15), CNS (13), GPR and GPC (5), Micrococcus (5), Acine- } \\
\text { tobacter (1) }\end{array}$ \\
\hline$E$ & NT & $\begin{array}{l}\text { CNS (93), Bacillus (31), Corynebacterium (29), Micrococcus (11), } \\
\text { GPR (2), NFR (1), S. aureus (1) }\end{array}$ \\
\hline
\end{tabular}

Type of doorknobs included grip-type (A), lever-type (B), two pull-types (C1 and C2), push-type (D), and insert-type (E).

CFU colony-forming unit, CNS coagulase-negative staphylococcus, NFR non-fermentative rods, GPR gram-positive rods, GPC gram-positive cocci, NT not tested.

\section{Discussion}

During all three seasons, there were significant differences in contamination among several types of clinical rooms (e.g., examination rooms and dressing rooms for radiological tests), and among several types of rooms on the wards (e.g., staff break rooms and lavatories), when comparing ATP levels on the same type of doorknob. We found no correlation between ATP levels on clinical-examination-room doorknobs and outpatient numbers, or between ATP levels at any monitoring point and microbial counts. The high ATP levels on clinical-examination-room doorknobs were decreased by cleaning after intervention by the ICT.

Omidbakhsh et al. [16] recently reported a limitation of the ATP assay for assessing decontamination of environmental surfaces in healthcare settings. Although the ATP method demonstrated acceptable linearity and repeatability, most of the disinfectant chemicals quenched or enhanced the ATP values variably in different settings. However, in the present study, there might have been less potential interference with disinfectant compounds, because the interval between the latest cleaning and ATP measurement was 7-21 h. When assessing contamination by ATP values, it is necessary to confirm the latest time of cleaning by disinfectants.

Watanabe et al. [14] studied hospital cleanliness in three Japanese hospitals that were specialized in longterm care. Based on ATP values and CFU per stamp medium, they showed that nursing stations, including the doorknobs, were cleaner than patient areas and public spaces, including the guardrail in the corridor. Our observations also indicated that nursing areas in wards were cleaner than public areas in clinics. Furthermore, there was no significant correlation between ATP values and numbers of inpatients in the previous study [14].
Similarly, we found no strong correlation between ATP values on doorknobs in clinical examination rooms and the numbers of outpatients.

Gastroenteritis (61 cases a year) associated with contamination of environmental surfaces was reported as an HAI in an old and architecturally unsatisfactory children's hospital [17]. In our study, we selected different monitoring periods because the incidences of bacterial gastroenteritis and food poisoning in the clinics and wards were presumed to show seasonal variation. There was a significant difference in contamination assessed by ATP values between the clinical examination rooms and staff-break rooms in the wards during each season. Thus, contamination monitoring needs to be performed regardless of the season. The main microorganisms found on the various doorknobs were coagulase-negative Staphylococcus, Bacillus, Corynebacterium, and Micrococcus in the wards and clinics. Appropriate disinfectants should be selected according to the data for microbial isolation.

It is likely that there has been little evaluation of the adequacy of routine housekeeping practices in some medical settings [11]. Previous investigations showed that cleaning of patient care areas was often suboptimal and that environmental surfaces appeared to remain contaminated with microorganisms after routine cleaning $[10,18-20]$. Based on the ATP values in our study, there was a significant difference in contamination between the clinical examination rooms and staff break rooms in the wards. We provided feedback in the form of the collected contamination data to the relevant housekeepers, and instructed them on the recommended cleaning methods. Although visual inspection of the cleaned surfaces is assumed to be adequate, the surfaces that meet visual criteria for cleanliness often remain contaminated with pathogens or other organic material [21]. Therefore, 
quantitative approaches including the ATP method are warranted for adequate evaluation of the effectiveness of cleaning practices [11, 21]. Huang et al. [22] compared visual inspection, aerobic CFU, and ATP assay to evaluate surface cleanliness at a medical center. The ATP assay was a sensitive and rapid tool for evaluating the quality of cleaning. In our study, after providing the housekeepers with relevant cleaning instructions, cleaning of doorknobs resulted in reduced ATP values in the clinical examination rooms and adjacent lavatories, although there was a limitation regarding a small number of second ATP values after cleaning instruction. When evaluating novel cleaning practices, baseline decontamination (i.e., the level of decontamination routinely achieved using normal cleaning procedures) must also be taken into consideration [13]. In this context, it is worth noting a recently reported assessment of daily cleaning practices using the ATP method in a hospital in a developing country [23]. This study suggests that visual assessment is not enough to ensure quality of the process and it is necessary to document the level of cleanliness by quantitative methods. However, ATP value should not be interpreted as a surrogate indicator for the presence of microbial pathogens [24].

\section{Conclusion}

We used an ATP assay to assess contamination of doorknobs in a hospital environment during different seasons. Doorknobs may become contaminated by frequent hand touching, resulting in HAIs. Comparison of ATP values on doorknobs showed significant differences in contamination among several types of clinical rooms and several types of rooms in wards during each of the three seasons. Our findings support the need for improvement of routine decontamination practice in clinical departments. We need to analyze further the relationship between HAI rates and doorknob contamination, assessed by ATP assay in clinics.

\section{Abbreviations \\ ATP: adenosine triphosphate; CFU: colony-forming unit; HAls: hospital- acquired infections; ICT: infection control team; RLUs: relative light units.}

\begin{abstract}
Authors' contributions
NK, MI, SH, and TT designed the study. NK, YH, SK, NY, and TT performed the sampling and assessment with the adenosine triphosphate bioluminescence assay. YH, SK, and TF performed technical assistance in culturing. YH conducted the statistical analyses. MI and NK supervised the practical work and data management. NK and TT wrote the manuscript. All authors read and approved the final manuscript.
\end{abstract}

\section{Author details}

1 Department of Infection Control and Prevention, Kitasato University Medical Center, 6-100 Arai, Kitamoto, Saitama 364-8501, Japan. ${ }^{2}$ Department of Clinical Laboratory, Kitasato University Medical Center, 6-100 Arai, Kitamoto, Saitama 364-8501, Japan. ${ }^{3}$ Laboratory of Infectious Diseases, Graduate School of Infection Control Sciences, Kitasato University, 5-9-1 Shirokane, Minato-ku, Tokyo 108-8641, Japan.

\section{Acknowledgements}

We thank the Japan Automatic Door Co., Ltd. for its assistance throughout this study.

\section{Compliance with ethical guidelines}

\section{Competing interests}

The authors declare that they have no competing interests.

Received: 19 March 2015 Accepted: 28 July 2015

Published online: 14 August 2015

\section{References}

1. Siegel JD, Rhinehart E, Jackson M, Chiarello L, Health Care Infection Control Practices Advisory Committee (2007) 2007 Guideline for isolation precautions: preventing transmission of infectious agents in health care settings. Am J Infect Control 35(Suppl 2):S65-S164

2. Samore MH, Venkataraman L, Degirolami PC, Levin E, Karchmer AW (1996) Clinical and molecular epidemiology of sporadic and clustered cases of nosocomial Clostridium difficile diarrhea. Am J Med 100:32-40

3. Martínez JA, Ruthazer R, Hansjosten K, Barefoot L, Snydman DR (2003) Role of environmental contamination as a risk factor for acquisition of vancomycin-resistant enterococci in patients treated in a medical intensive care unit. Arch Intern Med 163:1905-1912

4. Wu HM, Fornek M, Schwab KJ, Chapin AR, Gibson K, Schwab E et al (2005) A norovirus outbreak at a long term-care facility: the role of environmental surface contamination. Infect Control Hosp Epidemiol 26:802-810

5. Boyce JM (2007) Environmental contamination makes an important contribution to hospital infection. J Hosp Infect 65(Suppl 2):50-54

6. Sehulster $L, C$ Chinn RY, Centers for Disease Control and Prevention, Healthcare Infection Control Practices Advisory Committee (2003) Guidelines for environmental infection control in health-care facilities. Recommendations of CDC and the Healthcare Infection Control Practices Advisory Committee (HICPAC). MMWR Recomm Rep 52:1-42

7. Rutala WA, Weber DJ, The Healthcare Infection Control Practices Advisory Committee (HICPAC) (2008) Guideline for disinfection and sterilization in healthcare facilities, 2008. Centers for Disease Control and Prevention, USA

8. NHMRC (2010) Australian guidelines for the prevention and control of infection in healthcare. Commonwealth of Australia. ISBN Online: 1864965223. http://www.ag.gov.au/cca. Accessed 16 Mar 2015

9. Liz E (2012) Essential practice for infection prevention and control, guidance for nursing staff. 20 Cavendish Square London W1G ORN; RCN Direct 0345 772 6100: Published by the Royal College of Nursing. http://www. rcn.org.uk. Accessed 16 Mar 2015

10. French GL, Otter JA, Shannon KP, Adams NM, Watling D, Parks MJ (2004) Tackling contamination of the hospital environment by methicillin-resistant Staphylococcus aureus (MRSA): a comparison between conventional terminal cleaning and hydrogen peroxide vapour decontamination. J Hosp Infect 57:31-37

11. Boyce JM, Havill NL, Dumigan DG, Golebiewski M, Balogun O, Rizvani $R$ (2009) Monitoring the effectiveness of hospital cleaning practices by use of an adenosine triphosphate bioluminescence assay. Infect Control Hosp Epidemiol 30:678-684

12. Davidson CA, Griffith CJ, Peters AC, Fielding LM (1999) Evaluation of two methods for monitoring surface cleanliness-ATP bioluminescence and traditional hygiene swabbing. Luminescence 14:33-38

13. Moore G, Smyth D, Singleton J, Wilson P (2010) The use of adenosine triphosphate bioluminescence to assess the efficacy of a modified cleaning program implemented within an intensive care setting. Am J Infect Control 38:617-622

14. Watanabe R, Shimoda T, Yano R, Hayashi Y, Nakamura S, Matsuo J et al (2014) Visualization of hospital cleanliness in three Japanese hospitals with a tendency toward long-term care. BMC Res Notes 4(7):121 
15. Cheng KL, Boost MV, Chung JW (2011) Study on the effectiveness of disinfection with wipes against methicillin-resistant Staphylococcus aureus and implications for hospital hygiene. Am J Infect Control 39:577-580

16. Omidbakhsh N, Ahmadpour F, Kenny N (2014) How reliable are ATP bioluminescence meters in assessing decontamination of environmental surfaces in healthcare settings? PLoS One 9:e99951

17. Taylor MR, Keane CT, Kerrison IM, Stronge JL (1979) Simple and effective measures for control of enteric cross-infection in a children's hospital. Lancet 1:865-867

18. Malik RE, Cooper RA, Griffith CJ (2003) Use of audit tools to evaluate the efficacy of cleaning systems in hospitals. Am J Infect Control 31:181-187

19. Carling PC, Briggs JL, Perkins J, Highlander D (2006) Improved cleaning of patient rooms using a new targeting method. Clin Infect Dis 42:385-388

20. Carling PC, Parry MF, Von Beheren SM, Healthcare Environmental Hygiene Study Group (2008) Identifying opportunities to enhance environmental cleaning in 23 acute care hospitals. Infect Control Hosp Epidemiol 29:1-7
21. Griffith CJ, Cooper RA, Gilmore J, Davies C, Lewis M (2000) An evaluation of hospital cleaning regimes and standards. J Hosp Infect 45:19-28

22. Huang YS, Chen YC, Chen ML, Cheng A, Hung IC, Wang JT et al (2015) Comparing visual inspection, aerobic colony counts, and adenosine triphosphate bioluminescence assay for evaluating surface cleanliness at a medical center. Am J Infect Control. doi:10.1016/j.ajic.2015.03.027

23. Zambrano AA, Jones A, Otero P, Ajenjo MC, Labarca JA (2014) Assessment of hospital daily cleaning practices using ATP bioluminescence in a developing country. Braz J Infect Dis 18:675-677

24. Shama G, Malik DJ (2013) The uses and abuses of rapid bioluminescencebased ATP assays. Int J Hyg Environ Health 216:115-125

\section{Submit your next manuscript to BioMed Central and take full advantage of:}

- Convenient online submission

- Thorough peer review

- No space constraints or color figure charges

- Immediate publication on acceptance

- Inclusion in PubMed, CAS, Scopus and Google Scholar

- Research which is freely available for redistribution

Submit your manuscript at

www.biomedcentral.com/submit

C Biomed Central 